\title{
A How-To Guide for Electronic Reserves; Or, If I Knew Then What I Know Now
}

\section{Emilie R. Algenio MLS}

To cite this article: Emilie R. Algenio MLS (2002) A How-To Guide for Electronic Reserves; Or, If I Knew Then What I Know Now, Journal of Interlibrary Loan, Document Delivery \& Information Supply, 12:3, 1-12, DOI: 10.1300/J110v12n03 01

To link to this article: http://dx.doi.org/10.1300/J110v12n03_01

\section{Published online: 22 Oct 2008.}

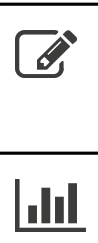

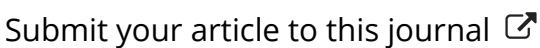

Wll Article views: 11

Q View related articles ¿

4 Citing articles: 1 View citing articles ๘ 


\title{
A How-To Guide for Electronic Reserves; Or, If I Knew Then What I Know Now
}

\author{
Emilie R. Algenio
}

\begin{abstract}
This presents a project-planning guide for librarians new to electronic reserves. It articulates an ideal process, organized into three major steps: research, implementation, and evaluation. Within the first step, all of the following topics are covered: people, equipment, campus dynamics, and copyright. Using a Socratic method, questions are posed to the reader, covering the essential issues. The goal is to assist the reader in determining how to begin and where to start. [Article copies available for a fee from The Haworth Document Delivery Service: 1-800-HAWORTH. E-mail address: <getinfo@haworthpressinc.com> Website: <http://www.HaworthPress.com> (C) 2002 by The Haworth Press, Inc. All rights reserved.]
\end{abstract}

KEYWORDS. Guide, electronic reserves, research, implementation, evaluation, copyright, staffing, campus climate, equipment

\section{PREFACE}

As the title indicates, the intention of this article is a project-planning guide for librarians embarking on the inception of an electronic reserves service. This endeavor is an articulation and overview of an ideal process, asking questions that will help the reader determine how to begin and where to start. The process is structured into three major phases, named Research, Implementation, and Evaluation. Within each phase,

Emilie R. Algenio, MLS, is Research Library Resident, Special Projects, W.E.B. Du Bois Library, University of Massachusetts Amherst, Amherst, MA 01003-9275 (E-mail: emilie@library.umass.edu).

Journal of Interlibrary Loan, Document Delivery \& Information Supply Vol. 12(3) 2002

(C) 2002 by The Haworth Press, Inc. All rights reserved. 
questions are posed that briefly cover the essential issues. Literature on this subject topic and experience indicate that the most work will be concentrated during the initial push to get started. Hence, the focus will be on Research and Implementation; Evaluation is the briefest phase.

Having accomplished this entire process over the course of one semester, the author wants to state a few points. The order of this process does not necessarily occur in totality, or in a chronological manner, or in a sequential fashion. The order of questions within each phase is intended to be logical. The answer to a question in one phase might be dependent on the answer(s) to another question from another phase. The degree of follow-up on a certain question is left to the reader's discretion. Finally, the author has assumed the context to be the library of either a college or a university; the latter is used throughout.

\section{RESEARCH}

This section contains four subsections, and will involve a discussion of these primary factors: people, equipment, campus dynamics and climate, and copyright.

\section{A. People}

\section{Students}

Goal: to understand your target audience. What do you know about your audience? What do students want from an electronic reserves service?

- What surveys have already, or could be, conducted about your own students? What segment of the population is the focus? Are any or all of the following surveyed: graduates, undergraduates, continuing education, distance education, and across different disciplines?

- Can you conduct a user needs assessment? What is the current makeup of your student body on- and off-campus? What is their technical proficiency? Are they information literate? How many are physically challenged? What is the level of your institution's commitment to using current technology? i.e., does your institution mandate every student to have a school computer account?

- Have you read the literature about student surveys? ${ }^{1}$ 


\section{Faculty}

Goal: to assess interest, keeping in mind who will be appropriate candidates for your pilot.

- Who supports the Library? Also uses new technology? Support this project?

- What will be the criteria in which they are judged as candidates or not? Perhaps ones that will support your project's guidelines, observe deadlines, or who are politically in tune with the Library?

- Who will be the best partners? Perhaps ones from the computer science, engineering, and education departments? Who's teaching distance education? What software are they using?

- Is the Library in competition with faculty who are using course software?

\section{Library Staff}

Preface: In the attempt to estimate how many staff you will need, the numbers will depend upon many factors. Specifically, they could be any or all of the following: available student hours to fill, speed and quality of equipment, amount of material to be scanned, the breakdown of responsibilities between professional and classified staff, the method of delivering e-reserves, whether or not you will use OCR software, and how many points of access you want to offer students.

Goal: to prepare the staff, who will support your new service.

- Before the research process starts, is it possible to involve the staff that will be running the service day-to-day, if the decision-makers of the service are different people from the staff who will be on the front lines?

- In which department will this service be located? Within the Library? Information Technology? Library IT? Reference? Reserve?

- What level of staffing is needed to cover the workload of this new service? 
- What level of staffing is necessary for the continuation, growth, and maintenance of this service?

- Will the staff be professional, classified, or student employees? How many of each?

- What is the monetary budget to increase staff to cover electronic reserves?

- Has the time to advertise, interview, hire, and train new staff been budgeted?

- Is your current staff enough to cover this, in addition to their current duties? How will the hours get covered as it expands?

\section{Staff Training}

- What is the level of technical skill/computer literacy of the front lines staff beyond their regular job duties?

- Is this new service an opportunity for staff training?

- How much time, money, and staffing can be spent of staff training?

- Who will train the staff? Staff development, systems, reference, University's IT? If you will use a commercial product, will the vendor offer free assistance?

- What hardware and software will they need to learn how to use?

- What kind of ready-made documentation and tutorials can be utilized?

- Will you train staff to the point of troubleshooting on their own? Or, at what point is it passed onto the systems department? Where are those limits? What process is in place for systems assistance? Will it be timely?

- Will they be dedicated to electronic reserves, or will their responsibilities and time be divided between the print Reserve department? If the latter is the case, what will that work schedule look like? Will it accommodate the ebb and flow of the department's workload throughout the semester?

\section{B. Equipment}

Goal: to make the necessary provisions, in terms of hardware and software, for delivering electronic reserves to the target audience.

- How do you want to offer electronic reserves? Use a commercial product or create a homegrown system? 
- If the decision-makers are not systems staff, did you solicit the opinion of the latter, regardless of the former's technical expertise?

- What does your Library currently own that can be utilized? Are new purchases necessary? What are the deadlines for the purchase order and the cost?

- What is available in the realm of commercial products? Disadvantages and advantages of each? In the course of researching the options, did you check electronic mailing groups for a product-specific users group and the subject topic? Call vendors for documentation and host on-site demos before purchasing? Determine who has this product locally? Visit them on-site and discuss advantages and disadvantages of their system?

- Are vendor expositions occurring locally, or are the companies actually based in your geographical area? Do they offer a point of comparison, a chance to use their product, an opportunity to surmise their marketing savvy?

- Do you have a free trial account, which includes an online demo available for staff to browse?

- What is the possibility for your site to be considered for beta testing? Will it work, with little monetary expense to your institution?

- Have you budgeted time between the point of purchase to the point of use? Allotting for purchase, installation, testing, debugging, and testing off-site?

- How compatible are the software and hardware with what is currently available within the Library-personal computers, Macs, the Library's automation system? Can it work across platforms?

- Will your method of delivery work across platforms? e.g., Can the data migrate smoothly to your library's automation system? Or will the data have to be manually entered?

- What are the minimal technical requirements for this to work? Maximum requirements?

- What can you afford?

- What will happen if the system crashes?

- What kind of backup and recovery is built-in?

- What will the workflow of the service be?

- Is documentation available for all equipment that is not already familiar with the staff that will be using it?

- How will you manage the document files of the reserve readings? Will you build a database of all necessary details? Could it also streamline the daily workflow? 


\section{Systems Staff}

- Does the vendor offer systems assistance? Is it free, pay-per-problem, on-site, via the telephone, or via e-mail? What are the hours of availability?

- Will they offer day-to-day help? Who will be the backup if the usual troubleshooter is not available?

- Who can provide assistance in a timely fashion?

- Who is responsible for the maintenance of the equipment used?

- What is the staff availability for back up if any part of the system fails?

\section{Vendor}

a. Overall

- What do you need the product to do? Want it to do?

- Does it include a user statistics feature? Does it generate reports, which include time stamps? Are they reader-friendly? Over what period of time are they available (to track the success or failure)?

- Is it affordable?

- How much customization is possible?

- Will it be ready to use by the start of the pilot?

- How does the product look and feel?

- How compliant is the product with the American Disabilities Act?

- Is it off-the-shelf? Or is it still in development?

- Is the product Web-based, or will it reside on a secure platform?

- What is the ease of use for students?

- What technical set up will be necessary for students and faculty to use this software?

- How many and what kind of file types does it support?

- What is the level of security level it offers?

- What developments are in the works?

b. Background

- What is the product's history? The company's history?

- Is it possible to have a copy of their annual report? Who are their competitors?

- What are the reputations of both the company and the product?

- Who are their other clients? Are their sizes comparable to yours? Are they peer institutions? 


\section{c. Copyright}

- How does the product deal with copyright? Are the built-in features in compliance with your copyright policies? How flexible is this feature? Do the features make it easy to manage its use or not?

- Do the copyright security features fall within the accepted limit of current digital copyright practices?

- Who has the responsibility for managing the copyrighted documents?

d. Help

- Is a product manual available?

- Does the vendor offer personal assistance? Is it free, pay-per-problem, on-site, via the telephone, or via e-mail? What are the hours of availability? Do they provide free training for staff?

e. Licenses for commercial products and their relationship to libraryowned databases

- Who is the resident expert on licenses? Has this person reviewed your commercial product's license in great detail?

- Who approves licenses?

- Has time been budgeted for this process, particularly if negotiations ensue? Will it affect your implementation timeline, or is the vendor willing to forward you a copy of their product before it is actually purchased?

- Of your licensed full-text databases, which ones employ persistent URL's for full-text articles? Do those database's licenses allow for electronic reserve use? For example, the author's institution owns licenses for Infotrac and JSTOR, both possess purl, and both licenses allow for use within an electronic reserves context.

\section{Campus Dynamics and Climate}

Goal: to understand how your project fits into the larger picture, and how the latter's dynamics and politics will affect the success of electronic reserves. 


\section{University-Level}

- Is your university moving towards distance education programs? If so, how quickly or slowly? At what level is it supported? In theory, but not in practice? Are there monetary incentives for faculty buy-in?

- Is your library a viable and visible partner in relation to the rest of campus?

- Given the recent plethora of course software, how much effort will the Library be duplicating? Is the Library in direct competition with this kind of activity?

- To avoid duplication of efforts, are there any similar projects underway in other departments? Across campus? What are the opportunities for partnership? What will be the pros and cons of this union? Who will benefit more?

- Have you assessed the political climate of your campus in terms of the budget to support new Library services?

- Do you have the support of your library director, and other campus administrators?

- Is this service part of, or could be part of, a consortium-wide or multi-campus effort? If so, how will it work?

\section{Library-Level}

- Does this service fall within purview of the Library's mission?

- What resources-time, money, people, space, and equipment-are already allocated to cover this service?

- Is this endeavor intended to a short-lived experiment, or will it be streamlined into a regular service? Has the aforementioned resources been allocated for both situations?

- Where will electronic reserves be physically located?

- Does that location have the capabilities, and is it outfitted, to accommodate the technology, equipment, and additional staff?

- In terms of managerial staff, do they support this project, from the lower ranks on through the upper ranks?

- What are your Library's practices and policies in terms of learning and supporting new technology? How is this different or similar in comparison to the attitudes of the staff?

\section{Copyright}

Preface: Given the wealth of library literature on this topic, the author chooses to make a few comments. The sole certainty is that the copyright landscape is volatile; current cases can change what looks like an apple to- 
day into an orange overnight. Unless you are a lawyer or law librarian, once you learn what this issue entails, you'll realize how much more you have yet to learn.

The author ventures to say that dealing with your faculty and this topic will be a learning experience unto itself. The notion that "Everything is free because we're an educational institution" is pervasive and compounded by the prevalence of course software in use. Librarians will encounter a wide range of awareness to this subset of intellectual property law-from the willful and blissfully ignorant to tech-savvy professors who routinely scan the World Wide Web for authorized use of their name.

Needless to say, the author recommends a proactive approach. What is crucial to understanding the issue of copyright? The answer is trying to see it from the following five viewpoints-lawyers, librarians, faculty, students, and authors/copyright owners. All have different interests and speak different languages.

- What, and how old, is your current copyright policy? Does it cover electronic reserves? Does it have your legal counsel's approval?

- Does your policy clarify the various responsibilities of the following: students, faculty, authors, OIT, and the Library? Does it cover all of the following scenarios: the classroom, the Textbook Annex, distance education "classrooms" (teleconferencing, etc.), the Library, and the Library classroom? Does it cover both print and electronic formats? Does it articulate what is legal and permissible, illegal and impermissible, and what is subject to disagreement and interpretation and attendant risk? Will it be practical enough so that front-lines staff can field questions?

- Will the Library's policy impede the IT policy of the University (in terms of faculty ownership)?

- Who will bear the responsibility of securing and paying for copyright permissions? If not the Library, will the department be charged for it? How will that work and be enforced as a procedure?

- If you are working within a multi-campus project or a consortium-who pays for it?

- Which staff member will be chosen for seeking and paying for permissions? A person from the legal department, legal counsel, within the Library, the law librarian, IT?

- What base of expertise will the staff person work from? Will they need training? 
- How will you deal with the issue of control? How much, or how little, does the library want to abdicate control to faculty? Are you aware of the legal consequences, in terms of faculty as a liability for copyright infringement?

- How will you deal with material that needs protection? How will you seek it?

- How will you deal with non-text formats, i.e., visual slides, mp3 files?

- How many points of access can you legally offer?

- How will you observe current copyright law?

- How will you employ fair use?

- Do you want to be conservative or liberal with this issue? Is your institution a big or small target?

- What are your legal responsibilities for using new technologies? Who will you have to answer to on-site if problems occur?

- Are you familiar with copyright management systems and how they operate? Will your equipment and security measures withstand their tests?

- Does your Library/university need a copyright education program? Will the focus be on the students, the faculty, the Library staff or the IT staff?

\section{IMPLEMENTATION}

- What do you want to accomplish by what time? Which semester do you want to implement this service? Will all major tasks-print processing, electronic processing, and all the equipment-be ready by that time?

- What is Plan B if Plan A does not work, in terms of delivery?

- Assuming your method of delivery has been chosen, purchased, installed, tested, and debugged, are all points of access functioning, on and off-site?

- If multiple libraries are using this service, where will the daily workload be physically located? Will it be centralized or decentralized? If it is the former, how do you intend to serve faculty from the branches?

- How do you plan to introduce this service? Attend the first class, or ask the instructor?

- What kinds of student and faculty assistance are in place? 
- Where should Electronic Reserves, as a Library service, be placed on the Library's web pages?

- How do you plan to advertise electronic reserves, keeping in mind the kind of customer service you can offer in relation to available resources (staffing, equipment, money)? How much can you handle? How many faculty can you service? Are any of the following possibilities for spreading the word: a sign at the Reserve desk, announcements at faculty meetings, campus publications, Library's web page(s), notifying your faculty liaisons?

- How important is it to market the Library beyond its current patron base?

- Once you have a strong base of faculty support, how do you plan to expand the service? Who can you target-departments currently supporting distance education, and/or faculty programs that award the use of new technology?

- At what point do you want to draft and implement Electronic Reserve guidelines, geared for your student and faculty audiences? Will the timing be in your favor? For example, if they are implemented in the inceptive stages, it could help you control the workload. However, your faculty might not appreciate if the rules are changed. If the guidelines are implemented farther down the road, the faculty might come to expect a turnaround time that the staff cannot meet.

- What will those guidelines include? Deadlines, method for submission, type of documents accepted, material format, length, copyright policy and procedure, turnaround time, parameters-class size, page length, required readings?

- If copyright guidelines are not in place, what will your response be to questions about the subject? Will this reply address the concerns of faculty who happen to have law degrees?

- Do you plan to document all numbers of the project? e.g., the time spent processing material from start to finish, how many document/files are available online, including the page totals, participating faculty, track user statistics.

\section{EVALUATION}

- For the pilot courses, can you conduct student surveys? Do the questions and answer choices effectively gauge how well your pilot worked? 
- For the pilot courses, will you conduct faculty surveys?

- For the actual reserve material, can you compare to print usage to its online counterpart?

- Does your method of electronic reserves delivery have a user statistics feature? Can that data be migrated into a spreadsheet easily?

- Is it possible to track statistics in regards to user assistance? e.g., maintain records of incoming calls, numbers of student e-mails needing help, etc.

- Did you use Net tracker to record the number of hits for the electronic reserve web pages?

- How do all of the aforementioned methods of evaluation-student surveys, faculty surveys, web page hits, electronic reserve user statistics, user frequency of assistance, and print Reserve use-compare to each other?

\section{NOTE}

1. Petersen, Lydia. What do students want from electronic reserves? Thesis (MSLS), University of North Carolina at Chapel Hill, 1997. 